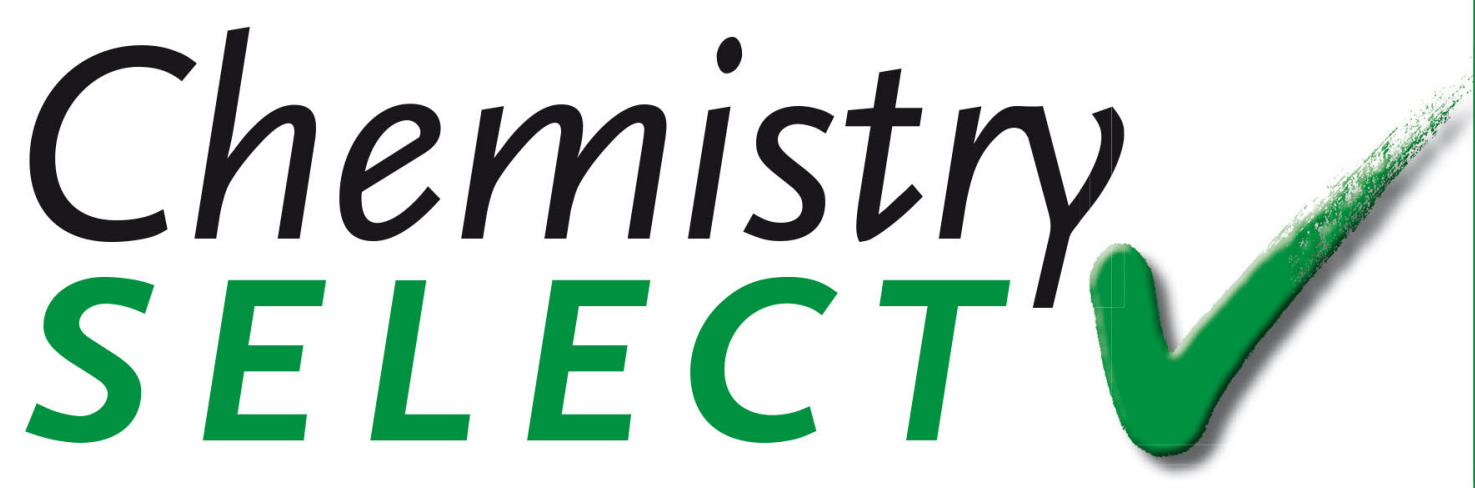

A journal of

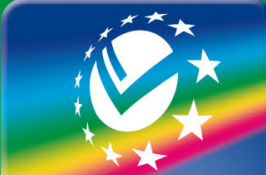

ChemPubSoc Europe

www.chemistryselect.org

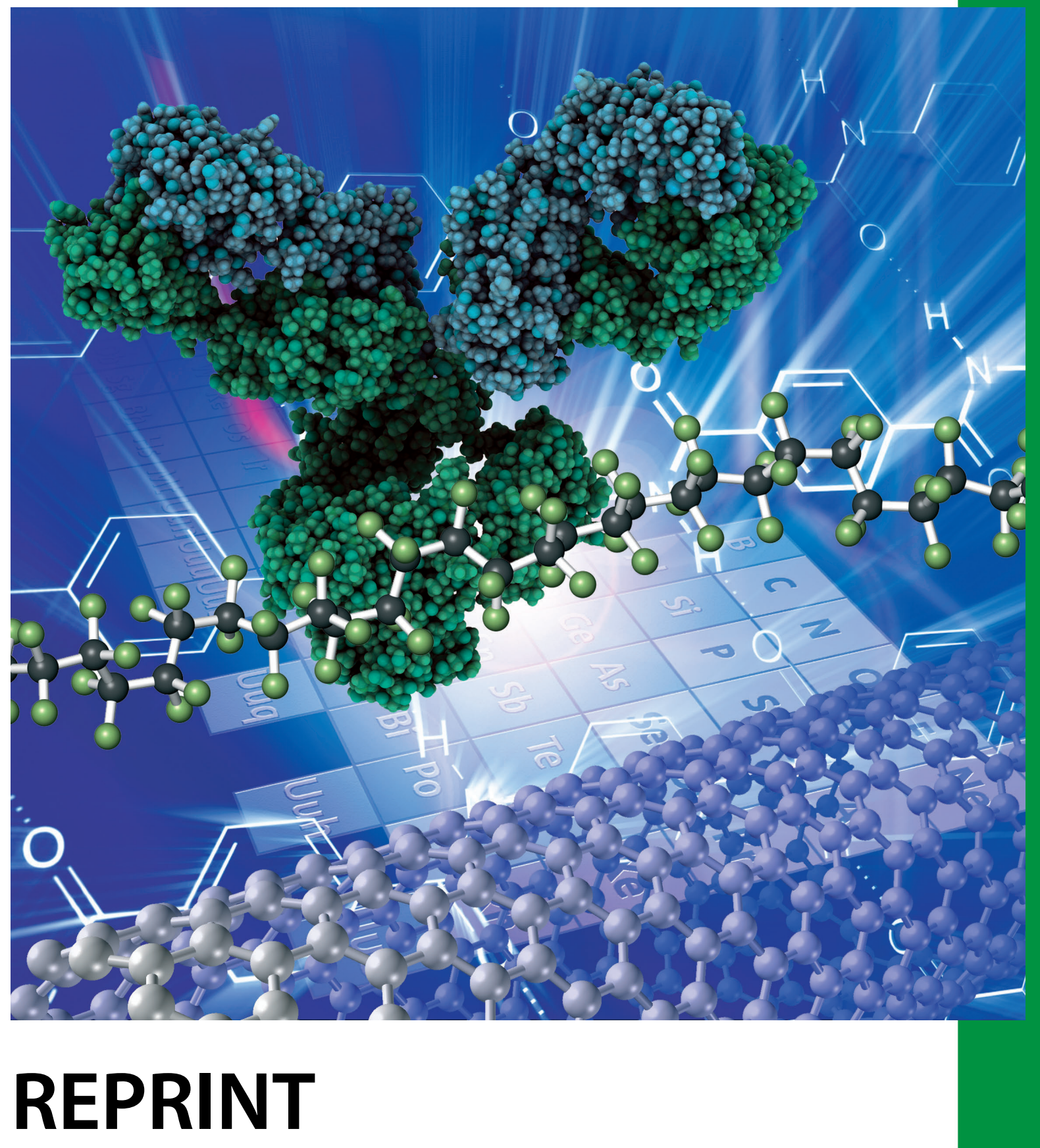

WILEY-VCH 


\title{
pH-Responsive Studies of Bacterial Cellulose /Chitosan Hydrogels Crosslinked with Genipin: Swelling and Drug Release Behaviour
}

\author{
Joachim E. Arikibe, ${ }^{[a]}$ Roselyn Lata, ${ }^{[a]}$ Keiichi Kuboyama, ${ }^{[b]}$ Toshiaki Ougizawa, ${ }^{[b]}$ and \\ David Rohindra*[a]
}

Semi interpenetrating hydrogels (semi-IPN) of bacterial cellulose $(\mathrm{BC})$ and chitosan (Ch) crosslinked with genipin were prepared and characterised using Differential Scanning Calorimetry (DSC), Fourier Transform Infrared Spectroscopy (FTIR) and Scanning Electron Microscopy (SEM). Infrared spectra showed amide I and II absorption peaks at 1632 and $1554 \mathrm{~cm}^{-1}$ and $\mathrm{C}-\mathrm{N}$ stretching absorptions at 1250 and $1020 \mathrm{~cm}^{-1}$, respectively, for crosslinked hydrogels. The fibrous structure of $\mathrm{BC}$ and the porosity in the hydrogels were revealed by SEM. Swelling of hydrogels was sensitive to $\mathrm{pH}$, and maximum at $\mathrm{pH}$ 1.0. Swelling of non-crosslinked samples decreased as the $\mathrm{pH}$ increased. However, with crosslinked hydrogels, swelling increased as chitosan ratio increased at low $\mathrm{pH}$, as well as with

\section{Introduction}

The synthesis of hydrogels consisting of natural polysaccharides and the search for properties suitable for different applications in biomedicine, pharmaceutics have gained considerable interest recently.

Cellulose, a water insoluble polysaccharide, ${ }^{[1,2]}$ is regarded as the most abundant organic compound in nature. Cellulose, which is often derived from plants, can also be synthesized by a variety of microorganisms such as bacteria, algae and fungi. ${ }^{[3-5]}$

Bacterial cellulose (BC) is a biosynthetic exopolysaccharide considered to be a purified form of cellulose. ${ }^{[6,7]}$ It is produced by various strains of bacteria of the Acetobacter genera: Agrobacterium, Aerobacter, Achromobacter, Azotobacter, Rhizobium, Sarcina and Salmolla. ${ }^{[1,2,8]}$ In recent times, most studies have used the Gram Negative bacteria, Gluconacetobacter xylinus (previously known as Acetobacter xylinum). It utilizes

[a] J. E. Arikibe, R. Lata, Dr. D. Rohindra

School of Biological and Chemical Sciences,

Faculty of Science Technology and Environment,

The University of the South Pacific, Suva, Fiji.

Tel.: +6793232867

Fax: + 6793231512

E-mail: rohindra_d@usp.ac.fj

[b] Dr. K. Kuboyama, Prof. T. Ougizawa

Department of Materials Science and Engineering,

Tokyo Institute of Technology, 2-12-1-S8-33, O-okayama, Meguro-ku, Tokyo 152-8552, Japan.

Supporting information for this article is available on the WWW under https://doi.org/10.1002/slct.201902290 increase in $\mathrm{BC}$ ratio at high $\mathrm{pH}$. Free, bound and intermediate water types in hydrogels were revealed by DSC. The release kinetics of Quetiapine fumarate (QF), an antipsychotic drug used for the treatment of Schizophrenia was studied using UV spectrometry, followed predominantly, the Higuchi model at all $\mathrm{pH}$ for crosslinked hydrogels. The transport mechanism of hydrogels was a combination of non-Fickian and Super Case II. Crosslinked hydrogels showed controlled drug release behaviour. These hydrogel systems possess potential application in pharmaceutical field as all chemicals used in the development of the hydrogels are non-toxic, with BC-Ch 60:40 showing most promising potential.

glucose as the substrate which is the most efficient producer of cellulose.$^{[3]}$ This bacteria is able to produce cellulose within a temperature range of $25-30{ }^{\circ} \mathrm{C}$ and $\mathrm{pH}$ range of $4.5-7.0 .^{[9]}$ Giving adequate consideration to its ultra-fine structure, $B C$ exhibits unique physico-chemical properties such as high tensile strength, crystallinity and high water absorption capacity. The superior features of $B C$ have enhanced its utilization in various applications. ${ }^{[7]} \mathrm{BC}$ has also been found to have received considerable attention in the field of biomedicine, ${ }^{[3,10]}$ because of its good biocompatibility properties. $^{[1]}$ It may be employed in the manufacture for artificial blood vessels for microsurgery, ${ }^{[12]}$ scaffolds for tissue engineering, ${ }^{[13,14]}$ and wound dressing for burns or wound repair. ${ }^{[7,15-17]}$ BC exhibits high stability, low toxicity, nonallergenicity and can be easily and safely sterilized.

However, the production of BC has been adversely affected by high cost and low yield. Researchers are searching for low cost nutrient with high yield production of BC.

Chitosan, a linear polysaccharide made up of $\beta$-(1-4)-linked D-glucosamine and N-acetyl-D-glucosamine, is a deacetylated form of chitin (>60\%). Chitin is a structural element that is a component of the exoskeleton of insects and crustaceans and found to be the second most abundant natural biopolymer after cellulose. ${ }^{[18]}$ The most exploited sources of chitin are the shells of crabs and shrimps. Because of its non-toxicity, stability, biodegradability, and similarity to the internal tissues of the body, chitosan has found itself as a very versatile material with extensive application in the biomedical and biotechnological fields. ${ }^{[19-21]}$ The swelling properties of chitosan have been 
controlled by crosslinking using crosslinking agents such as glutaldehyde, ${ }^{[22]}$ and genipin. ${ }^{[23]}$ These attractive properties also make the polymer an ideal candidate for controlled release formulations.

Research in BC and chitosan hydrogels is an emerging area. BC-chitosan hydrogels have been developed and tested for miscibility, ${ }^{[24]}$ as cell scaffold material, ${ }^{[25]}$ anti-bacterial feature which could be used in tissue engineering, ${ }^{[26]}$ and degradation by Candida rugosa lipase. ${ }^{[27]}$

Biodegradable polymers such as chitosan need to be crosslinked in order to modulate their general properties and to last long enough for delivering drug over a desired period of time such as the $\mathrm{BC}-\mathrm{Ch}$ system in the present study. Crosslinkers such as glutaraldehyde, tripolyphosphate, ${ }^{[28]}$ ethylene glucol, diglycidyl ether and diisocyanate have been used. However, these synthetic crosslinking reagents are all more or less cytotoxic, may impair the biocompatibility of hydrogels delivery systems and their crosslinked products have been found to show limited stability. ${ }^{[29]}$ Thus, there is a need for a natural crosslinking agent that is nontoxic and that forms stable and utterly biocompatible crosslinked products. An alternative choice is genipin, a natural product with low cytotoxicity. Its use in hydrogels eliminates the effects of cytotoxicity and inflammatory responses. ${ }^{[30,31]}$

Genipin-crosslinked chitosan system and chitosan-cellulose blends and hydrogel systems have been extensively studied. However, based on our literature search, there is no reported work on genipin-crosslinked bacterial cellulose-chitosan hydrogel which is completely biocompatible, nontoxic, with improved properties and behaviour in terms of swelling andstability for the kinetic release study of Quetiapine fumarate at different physiological $\mathrm{pH}^{\prime}$ s. The purpose of this study was to prepare semi-IPN hydrogels consisting of BC and chitosan, crosslinked with genipin, a non-toxic compound, and investigate the swelling properties and drug release behaviour of Quetiapine fumarate at different $\mathrm{pH}^{\prime} \mathrm{s}$.

\section{Results and Discussion}

\section{Microbial screening of the BC}

The BC formed was removed from the fermenting container and washed with distilled water. To ascertain the safety of the produced $\mathrm{BC}$, microbial screening was conducted. The overall number of bacteria, number of molds and yeast and the different types of bacteria; Enterobacteriaceae and other negative bacilli (-), Escherichia coli, Staphylococcus aureus and Pseudomonas aeruginosa were all below the required levels or absent.

\section{Physical appearance of non-crosslinked BC-Ch samples and crosslinked BC-Ch hydrogels}

As shown in Figure 1, the $\mathrm{BC}-\mathrm{Ch}$ hydrogel crosslinked with genipin was dark-blue in colour due to exposure of the material to air which is associated with oxygen-induced polymerization of genipin as well as the reaction of genipin with the

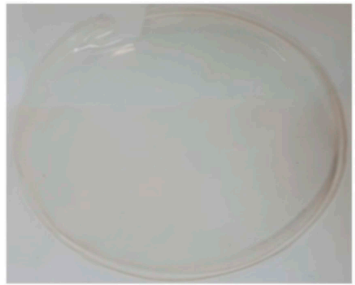

Non-crosslinked sample

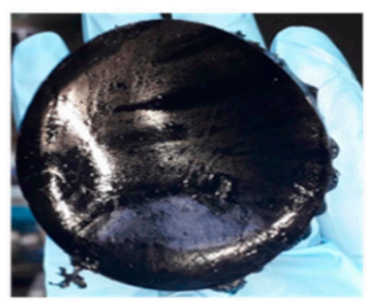

Crosslinked hydrogel
Figure 1. Physical appearance of the non-crosslinked sample and crosslinked hydrogel

nucleophilic amino $\left(\mathrm{NH}_{2}\right)$ groups of chitosan. ${ }^{[21,32]}$ However, the non-crosslinked sample was transparent in appearance.

The ring-opening reaction results in the formation of new $\mathrm{N}-\mathrm{H}$ and $\mathrm{C}-\mathrm{N}$ linkages. The system prepared is a semi interpenetrating network, where the $\mathrm{BC}$ incorporates itself into the crosslinked chitosan network by physical entanglements and intermolecular forces.. Figure 2 shows the reaction scheme for the formation of the semi-IPN hydrogels.

\section{FTIR Analysis of the BC-Ch hydrogels}

The infrared spectra of the $\mathrm{BC}$, chitosan and $\mathrm{BC}-\mathrm{Ch}$ noncrosslinked samples and crosslinked hydrogels are shown in Figure 3. Both BC and chitosan have almost similar IR spectra due to their similarity in chemical structure. However, the regions of interest for this study were around 3500, 1600 and $1500 \mathrm{~cm}^{-1}$ that showed some characteristic peaks for BC and chitosan. The band around $3342 \mathrm{~cm}^{-1}$ is due to the stretching of the $\mathrm{OH}$ group. After blending $\mathrm{BC}$ with chitosan, the $\mathrm{OH}$ peak remained quite unaffected (not pronounced shift in wavenumber) but crosslinking with genipin shifted it to lower wavenumbers. The peak at $1625 \mathrm{~cm}^{-1}$ in $\mathrm{BC}$ was due to $\mathrm{OH}$ bending of absorbed water molecules. ${ }^{[33]}$ This peak shifted to higher wavenumbers to around $1643 \mathrm{~cm}^{-1}$ when blended with chitosan. This shift can be attributed to the peak overlapping and interactions occurring between $\mathrm{OH}$ bending of water molecules with $\mathrm{OH}$ groups in $\mathrm{BC}$ and that of chitosan. In chitosan, the peaks at 1649 and $1579 \mathrm{~cm}^{-1}$ are attributed to the amino $\left(\mathrm{NH}_{2}\right)$ and $\mathrm{N}-\mathrm{H}$ bending vibrations respectively. After crosslinking, the emergence of the peaks at 1632 and $1554 \mathrm{~cm}^{-1}$ confirmed the formation of the amide I and amide II representing the moieties of the amino group. Furthermore, the peak observed at $1025 \mathrm{~cm}^{-1}$ is distinctly attributed to the $\mathrm{C}-\mathrm{N}$ stretching resulting from the crosslinking interaction between genipin and chitosan. This peak was absent in $B C$ and the non-crosslinked samples. Considering that BC and chitosan share similar structures and mutually complementary qualities (Figure 2), their combination results in reinforced molecular interaction between the polysaccharides via hydrogen bonding and other physical entanglements. This confirmed that crosslinking the chitosan in the presence of $B C$ resulted in a semi interpenetrating network hydrogel. 
Chitosan

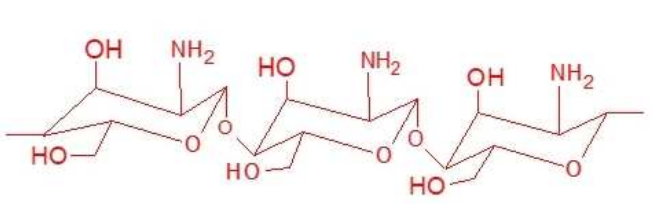

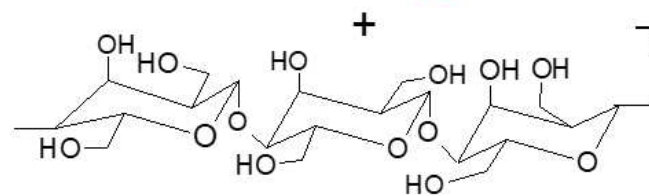

Bacterial cellulose
Genipin

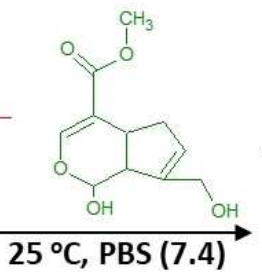

Semi-IPN hydrogel

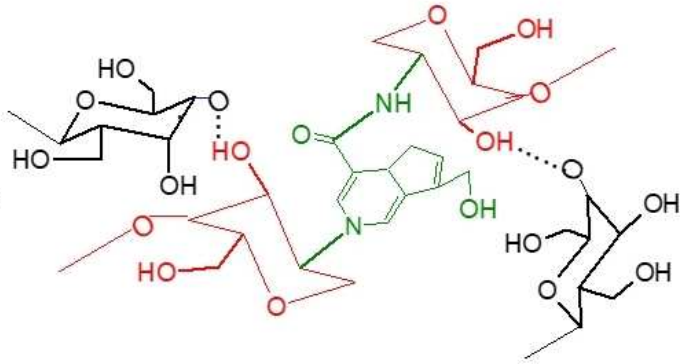

Figure 2. Reaction scheme for the formation of the semi-IPN hydrogels.

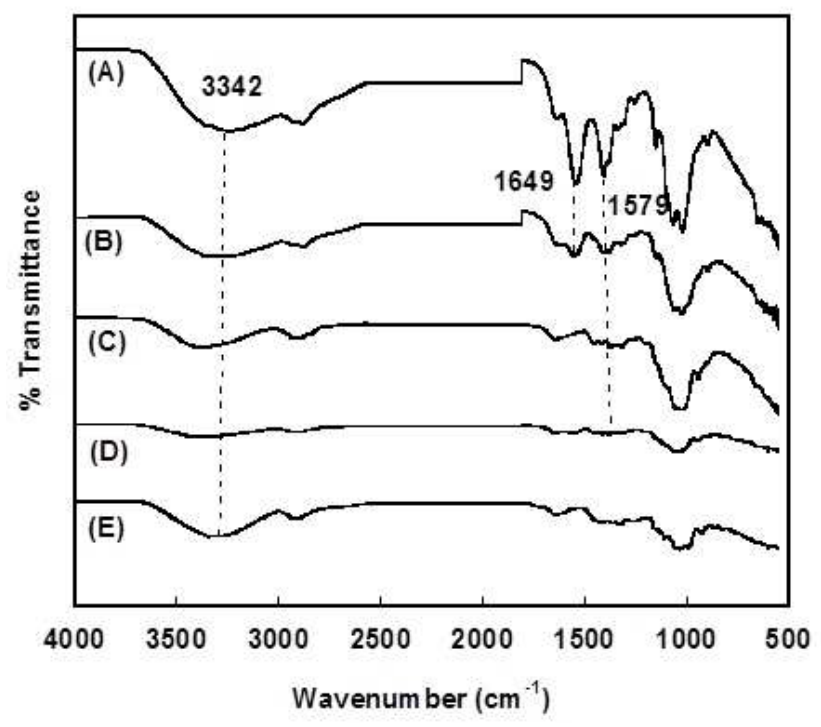

Figure 3. FT-IR absorption peaks for $B C$, chitosan and $B C-C h(\% \mathrm{w} / \mathrm{w})$ hydrogels. (A) Ch UCL (B) Ch CL (C) 60:40 UCL (D) 60:40 CL (E) BC. First value is $B C$ and last value is chitosan. (NB: $C L$ and $U C L$ represent crosslinked and non-crosslinked, respectively)

QF is an antipsychotic drug for treating schizophrenia and the chemical structure is shown in Figure 4. QF is administered twice a day and the problem of patients skipping doses has been reported in most cases. ${ }^{[34,35]}$ Hence, the need for a delivery system for QF that could offers extended release (ER), minimize side effects due to over-dosage with improve compliance in schizophrenia patients and in which QF does not have any chemical interactions with the hydrogel matrix.

For the drug QF, FT-IR analysis showed the characteristic peaks at 1600,766 and $745 \mathrm{~cm}^{-1}$ which are attributed to presence of substituted benzene ring. Figure 5 shows the IR spectra of $\mathrm{QF}, \mathrm{BC}-\mathrm{Ch}$ hydrogels with and without QF. The emergence of the characteristic QF peaks in the hydrogel confirmed the presence of the drug.

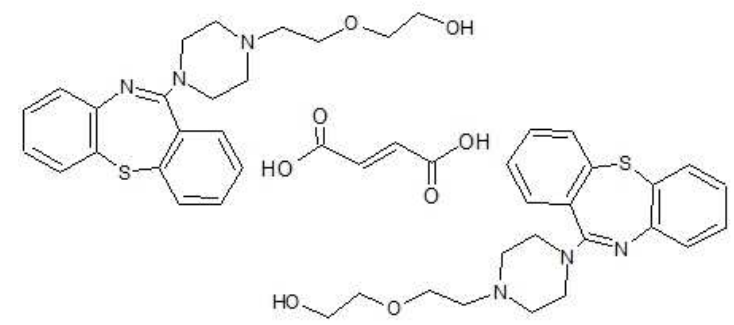

Figure 4. The chemical structure of Quetiapine fumarate

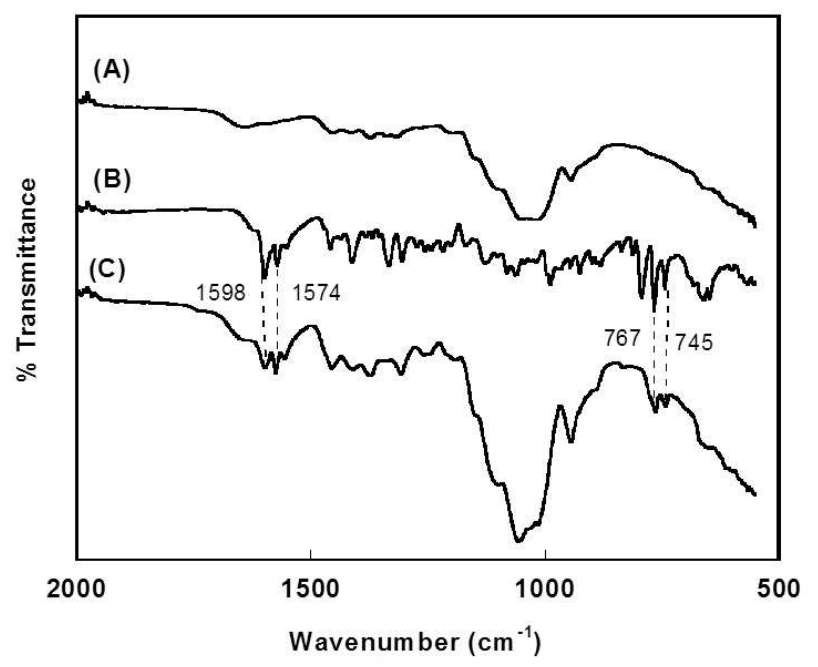

Figure 5. FTIR spectra for (A) BC-Ch 60:40 (\% w/w) hydrogel without QF; (B) QF and (C) BC-Ch 60:40 (\% w/w) hydrogel loaded with QF. (First value is BC and last value is chitosan)

Furthermore, the unchanged positon of the QF's distinct absorption peaks in the hydrogel matrix suggested QF maintained its distinct identity and did not interact chemically with the biopolymers (matrix) but only via intermolecular hydrogen bonding. 

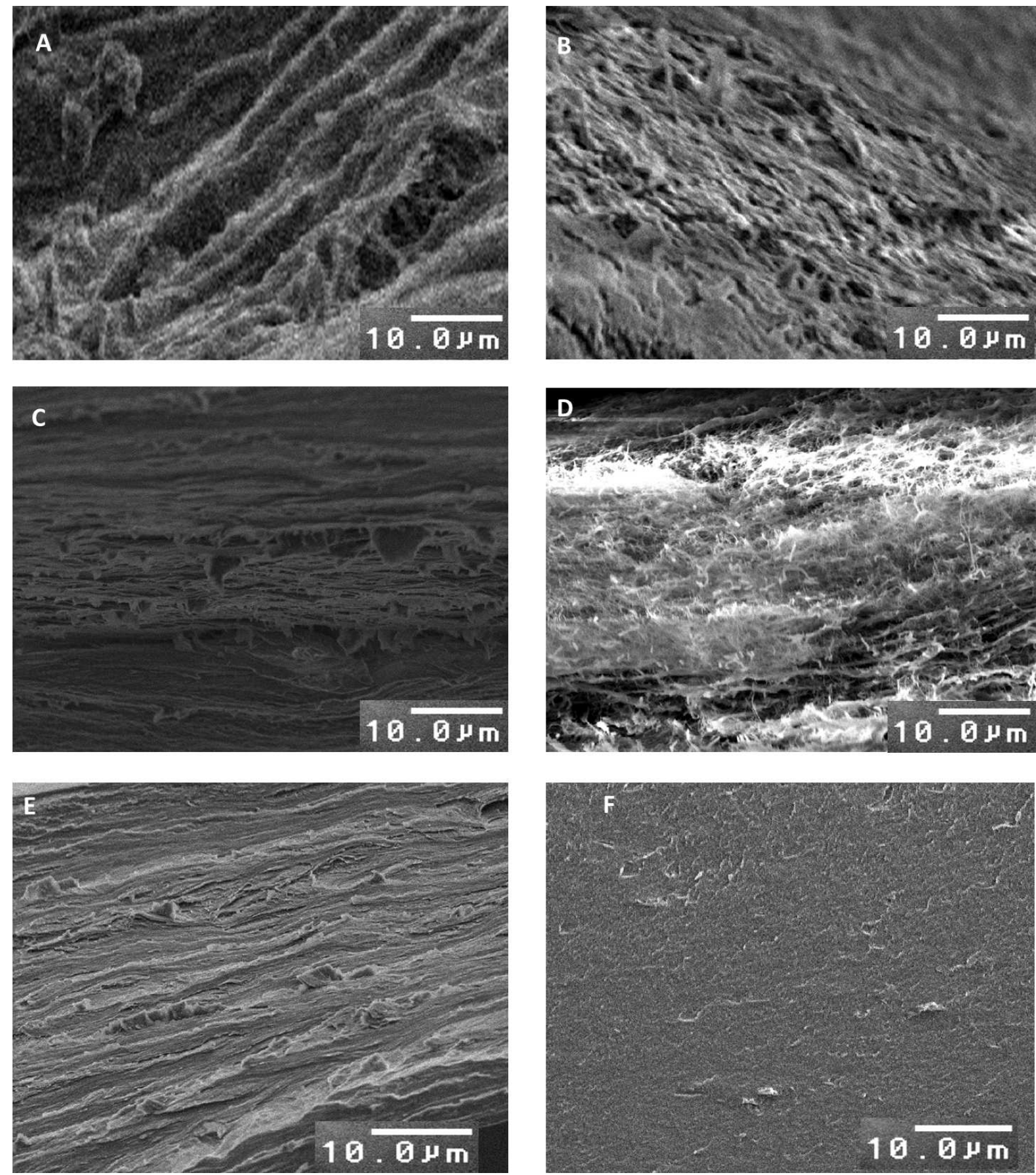

Figure 6. SEM images of BC, chitosan and BC-Ch (\% w/w) hydrogels (A) BC, (B) 80:20 UCL, (C) 80:20 CL (D) 60:40 UCL, (E) 60:40 CL and (F) chitosan (Magnification 1000x). (First value is $B C$ and last value is chitosan).

\section{Scanning Electron Microscopy}

The SEM images of pure $\mathrm{BC}$ and $\mathrm{BC}-\mathrm{Ch}$ non-crosslinked samples and crosslinked hydrogels are presented in Figure 6A F. BC membrane was found to possess a network of fibrils. The $B C$ structure observed here agrees with that reported in literature. ${ }^{[36]}$ The SEM revealed the extent of compactness in the structure of the crosslinked hydrogels (Figure $6 C$ and E) due to the crosslinking of chitosan by genipin within the semi-
IPN leading to a decrease in the observed pore sizes of the hydrogels as opposed to the non-crosslinked samples (Figure $6 \mathrm{~B}$ and $\mathrm{D}$ ) which showed little compactness and are similar to that observed for pure $B C$.

\section{Gel Fraction of hydrogels}

Figure 7 shows the gel fraction of the hydrogels containing different amounts of BC and chitosan. Gel fraction increased 


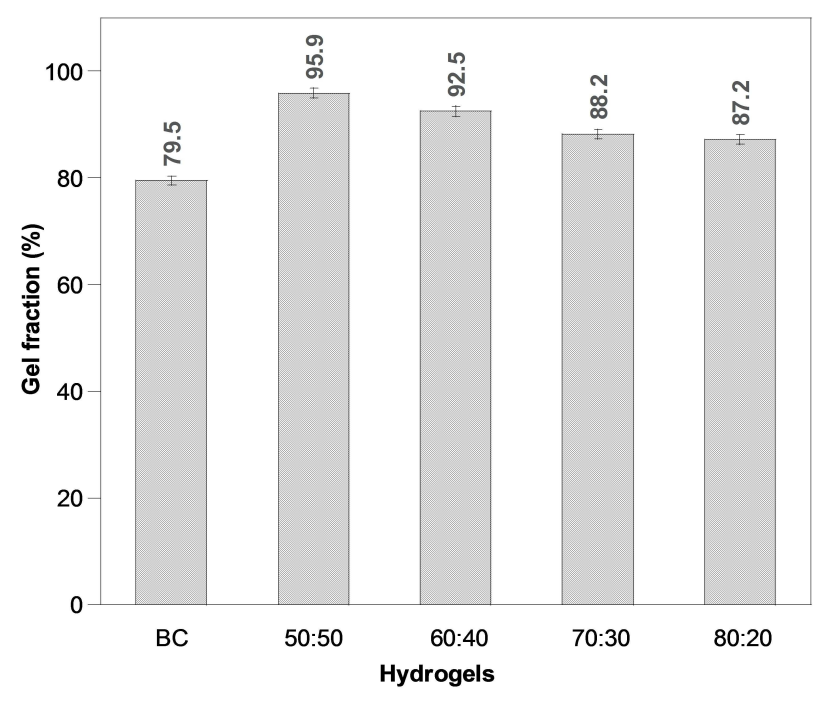

Figure 7. Gel fraction of $B C-C h(\% \mathrm{w} / \mathrm{w})$ hydrogels. (First value is $\mathrm{BC}$ and last value is chitosan).

with increasing chitosan content in the hydrogel as a result of the availability of sites for crosslinking to occur. This implies that, as the content of chitosan increased in the hydrogels, crosslinking became more pronounced and the amount of unreacted components in the hydrogels decreased since chitosan is the crosslinked component in the hydrogel network. Also, in combination, there might have been an increase in the water holding capacity and gelling property of the combined polymers, resulting to the observed high value of gel fraction as reported by Wahid et al. ${ }^{[26]}$ This observed behaviour explains why the gel fraction in the present study was maximum in BCCh 50:50 hydrogel. Similar behavior has been reported for carboxymethyl chitosan/poly (acrylonitrile) semi-IPN hydrogels. ${ }^{[37]}$

\section{Swelling Behaviour of the Hydrogels}

Sensitivity to water and other biological fluids remains the most important property of hydrogels that determine their practical applicability in diverse areas. The swelling behavior of BC, chitosan and BC-Ch (80:20 and 60:40) crosslinked hydrogels and non-crosslinked samples in different artificial gastrointestinal media of varying $\mathrm{pH}$ are presented in Figure 8A-D. All the hydrogels exhibited high swelling in the different media. Noticeably, BC maintained the highest swelling in all the media, because of the interactions between the $\mathrm{OH}$ groups of $\mathrm{BC}$ and water molecules, making $B C$ high in water permeability. Although $B C$ and plant cellulose have the same chemical structures, however, BC possesses macromolecular properties different from plant cellulose. The thin microfibrils of $B C$ are significantly smaller than those in plant cellulose, making $B C$ much more porous than plant cellulose. ${ }^{[38]}$ The high aspect ratio of $B C$ fibrils provided $B C$ with high swelling ability, which resulted in high water holding capacity. ${ }^{[29,38,39]}$
At $\mathrm{pH}$ values (1.0 and 4.5), the non-crosslinked samples recorded the highest swelling compared to the crosslinked hydrogels. This is because the polymer chains were flexible and relaxed due to the absence of crosslinking, ${ }^{[22]}$ allowing more fluid to go into the polymer networks. Hydrogels with high chitosan content showed increased swelling at low $\mathrm{pH}$. This is because the $\mathrm{NH}_{2}$ groups of chitosan got protonated resulting in polymer-polymer chains repulsion, thereby making chitosan a water-soluble cationic polyelectrolyte which resulted in allowing more fluids into the hydrogels network. At low $\mathrm{pH}$, the amount of protonated positive charges - $\left(\mathrm{NH}_{3}^{+}\right)$in chitosan is observed to be highest because there are more extensions of the chains, ${ }^{[37]}$ increasing the hydrodynamic volume of the hydrogels. For the crosslinked hydrogels, a decrease in swelling was observed and is attributed to the effect of genipin crosslinking the chitosan within the hydrogel networks which reduced the water permeability of the hydrogels. The crosslinking of chitosan with genipin results in both hydrophilic and hydrophobic interactions. These interactions involve the hydrophobic methyl group, dihydropyran ring as well as hydrophilic groups such $\mathrm{OH}$, amine, amide, and the amphiphilic polymers behaviour within the hydrogels, thereby bringing about a reduction in water absorbency. ${ }^{[33,40]}$ In this context, the fluid content of the hydrogels may have altered the chemical potential as a result of elastic forces, which are responsible for change of volume fraction density of the polymer chains in the crosslinking process.

At $\mathrm{pH}$ values (6.8 and 7.0), the swelling of the hydrogels increased with increasing $B C$ content in both the crosslinked hydrogels and non-crosslinked samples. The non-crosslinked samples showed higher swelling compared to the crosslinked hydrogels. At these pHs the swelling was minimum in hydrogels with high chitosan content. This is because the cationic property of chitosan is diminished, thereby leaving chitosan less protonated resulting in smaller hydrodynamic volume. The swelling is suggested to be due to the hydrophilicity provided by the higher $\mathrm{BC}$ contents in the hydrogels. When $\mathrm{pH}$ is raised to a value higher than 6 , the $\mathrm{NH}_{2}$ groups in chitosan are deprotonated and there is loss of charge on the polymer, thus becoming insoluble. The soluble-insoluble transition takes place at $\mathrm{pH}$ values near the pKa value of chitosan, which is around 6-6.5. ${ }^{[4]]}$ This deprotonation of the amino groups in chitosan recede repulsion in polymer chains which brings about shrinking of the hydrogel. ${ }^{[2]}$ The variations in the swelling behaviour of the hydrogels indicated that the swelling is $\mathrm{pH}$ sensitive with respect to chitosan but independent with respect to $B C$. Swelling decreased significantly in the noncrosslinked samples as the $\mathrm{pH}$ increased. However, with the crosslinked hydrogels, blends with increasing chitosan content swelled more at low pH's (1.0 and 4.5) while blends with higher $\mathrm{BC}$ content swelled more at high $\mathrm{pH}$ 's $(6.8$ and 7.0$)$. The swelling behaviours of non-crosslinked samples and crosslinked hydrogels 70:30 and 50:50 were similar to that of $80: 20$ and 60:40. 

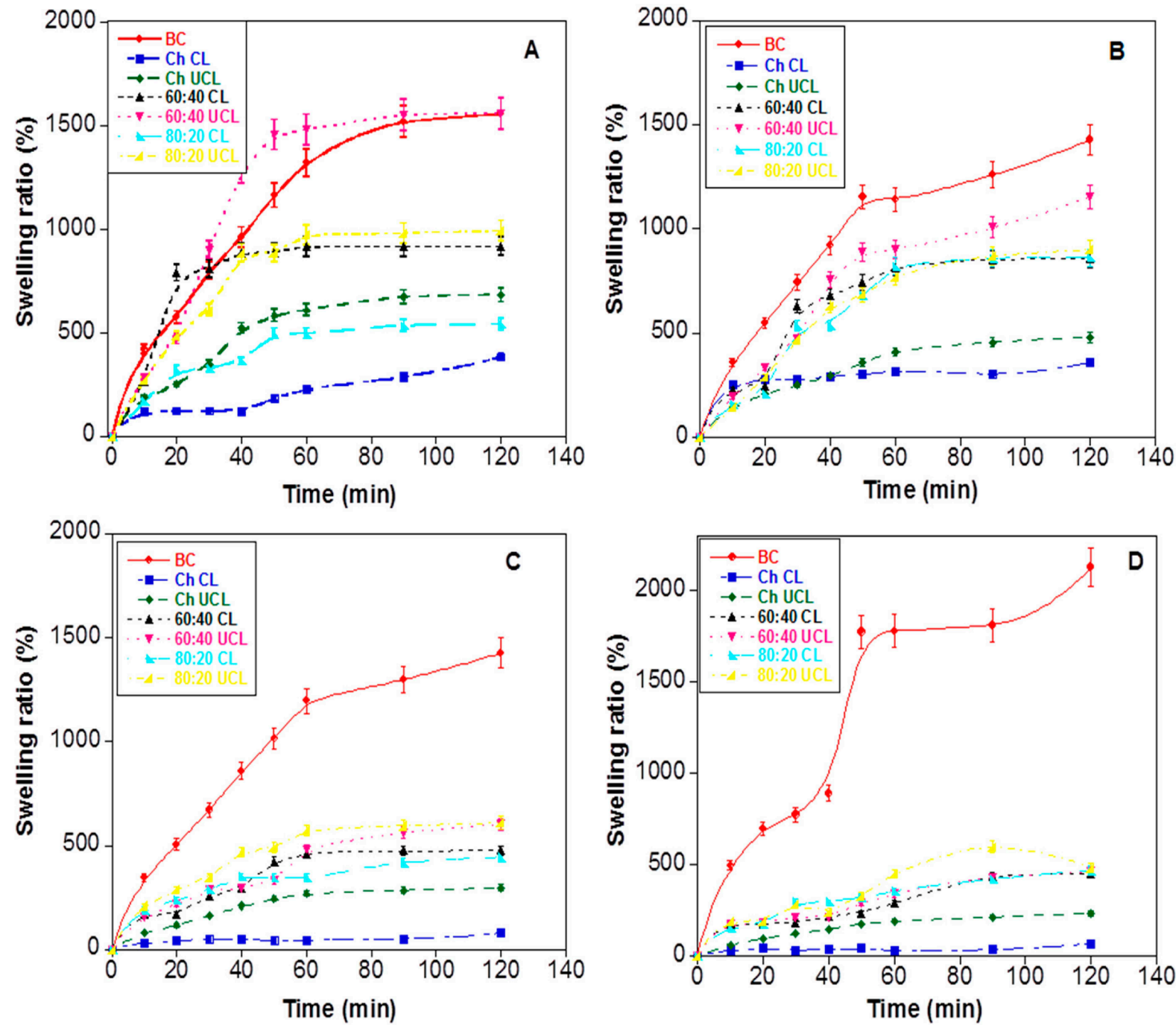

Figure 8. Swelling ratio of non-crosslinked (UCL) and crosslinked (CL) BC-Ch (\% w/w) hydrogels at (A) pH 1.0 (B) pH 4.5 (C) pH 6.8 and (D) pH 7.0. (First value is $B C$ and last value is chitosan).

\section{Thermal behavior of the water in the swollen hydrogels}

Figure $9 \mathrm{~A}$ and $\mathrm{B}$ shows the normalized heating profiles of the swollen non-crosslinked samples and crosslinked hydrogels, respectively, after being cooled to $-50^{\circ} \mathrm{C}$ and heated at a rate of $10^{\circ} \mathrm{C} \mathrm{min}^{-1}$. In the non-crosslinked samples, only one endothermic peak was observed around $0^{\circ} \mathrm{C}$ while for the crosslinked hydrogels, two endothermic peaks were observed, one at lower temperature around $-10^{\circ} \mathrm{C}$ and the other around $0^{\circ} \mathrm{C}$.

It has been reported, ${ }^{[22]}$ that three types of water exist in hydrogels and are referred to as free, intermediate and bound water. Free water freezes upon cooling to low temperatures and shows a melting endotherm in the DSC heating scan at $0^{\circ} \mathrm{C}$. Intermediate water represents water molecules that form weak interactions with the polymer molecules of the hydrogels and the frozen segment shows a melting endotherm less than $0^{\circ} \mathrm{C}$. Bound water also referred to as non-freezing water is the type that forms strong interactions with the hydrogel and does not freeze upon cooling, consequently shows no melting endotherm. Non-crosslinked samples showed a single endothermic peak which ranged from 0 to $10^{\circ} \mathrm{C}$ for chitosan to $\mathrm{BC}$, respectively. Crosslinking is basically responsible for the 3-D networks of hydrogels and other entanglements of the polymers and it is the dominant factor that impacts on all features of hydrogels, including the nature or types of water that can be found within a hydrogel system. The noncrosslinked BC-Ch systems showing only one type of water may not be unconnected to the absence of a 3-D network typically found in hydrogels and other entanglements brought about by crosslinking that result from interaction between $B C$ and chitosan. As a result, non-crosslinked systems do not possess the network for the water structured in the "ice-cage" conformation. ${ }^{[42,43]}$ However, the onset temperature of the endothermic peaks was at $0^{\circ} \mathrm{C}$. Interestingly, crosslinked hydrogels showed the presence of both intermediate and free water. 

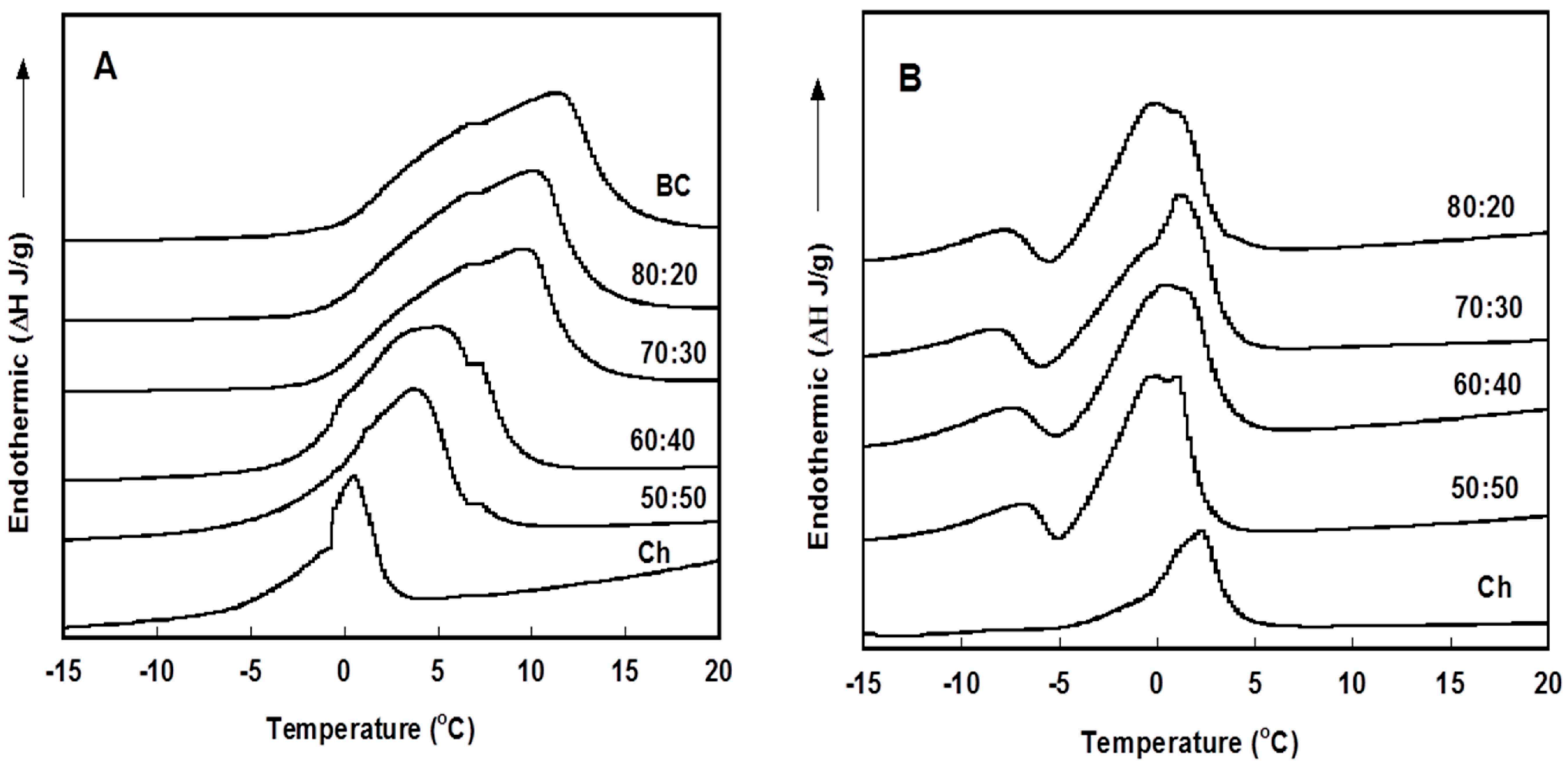

Figure 9. The heating profiles of $B C-C h(\% \mathrm{w} / \mathrm{w})(\mathrm{A})$ non-crosslinked and (B) crosslinked hydrogels. (First value is $\mathrm{BC}$ and last value is chitosan).

The free water melted at $0{ }^{\circ} \mathrm{C}$. The size of the endothermic peak corresponding to the intermediate water was found to increase with increasing chitosan content and is suggested to be due to the entrapment of water molecules in the network and forming weak hydrogen bonds.

The different types of water present in non-crosslinked samples and crosslinked hydrogels of different ratios are listed in Table 1. The equilibrium water content (ECW) (\%) of non-

\begin{tabular}{|c|c|c|c|c|}
\hline Sample & $\begin{array}{l}\text { EWC } \\
(\%)\end{array}$ & $\begin{array}{l}\text { Free water } \\
\text { (\%) }\end{array}$ & $\begin{array}{l}\text { Bound water } \\
\text { (\%) }\end{array}$ & $\begin{array}{c}\text { Intermediate } \\
\text { water (\%) }\end{array}$ \\
\hline$B C$ & 95.10 & 91.50 & 3.60 & - \\
\hline Ch UCL & 39.13 & 31.73 & 7.40 & - \\
\hline $\begin{array}{l}50: 50 \\
U C L\end{array}$ & 70.20 & 57.90 & 12.30 & - \\
\hline $\begin{array}{l}60: 40 \\
\text { UCL }\end{array}$ & 87.30 & 88.70 & $\begin{array}{l}\text { Deviation ob- } \\
\text { served }\end{array}$ & - \\
\hline 70:30UCL & 88.10 & 93.30 & $\begin{array}{l}\text { Deviation ob- } \\
\text { served }\end{array}$ & - \\
\hline $\begin{array}{l}80: 20 \\
\text { UCL }\end{array}$ & 88.20 & 96.41 & $\begin{array}{l}\text { Deviation ob- } \\
\text { served }\end{array}$ & - \\
\hline $\mathrm{Ch} \mathrm{CL}$ & 27.24 & 8.16 & 19.08 & - \\
\hline $50: 50 \mathrm{CL}$ & 72.50 & 42.70 & 25.10 & 4.70 \\
\hline $60: 40 \mathrm{CL}$ & 73.10 & 45.00 & 23.80 & 4.30 \\
\hline 70:30 CL & 75.70 & 56.20 & 16.90 & 2.60 \\
\hline $80: 20 \mathrm{CL}$ & 77.80 & 62.00 & 14.50 & 1.30 \\
\hline
\end{tabular}

crosslinked samples was higher than those of the crosslinked hydrogels. An increase in ECW (\%) was observed in both crosslinked hydrogels and non-crosslinked samples as the amount of BC increased and is suggested to be due to the hydrophilic contribution of $B C$ and its porous nature. Only the crosslinked hydrogels contained intermediate water in their matrix and was observed to increase as the amount of chitosan increased. This is possibly due to the entrapment of water within the entanglement created between genipin crosslinked chitosan and $B C$ and the hydrophilic groups of the polymer chains forming intermolecular forces with water. Free water in crosslinked hydrogels increased as the amount of BC increased while bound water increased as ratio of chitosan increased. However, an unusual phenomenon was observed in the $\mathrm{BC}-\mathrm{Ch}$ $60: 40, B C-C h \quad 70: 30$ and BC-Ch 80:20, where the calculated amount of free water was found to be higher than the ECW. The suggestion to this observation may be during freezing, as the volume of water expanded (ice has higher volume than liquid water), the polymer chains also rearranged due to stress imposed by the expanding water. Upon heating, the endothermic peak at $0{ }^{\circ} \mathrm{C}$ contains both the heat required for melting ice and for polymer chain relaxation. The combined heat could be the reason for the observation of this phenomenon.

\section{In vitro Drug release kinetic and transport mechanism}

Kinetic models (Higuchi, First Order, Zero order, Hixson) are used to show forms of drug release and transport mechanism involved in matrice of diverse geometries and compositions. These models are based on different mathematical functions. The Higuchi model describes the drug release as a diffusion process based on Fick's law. The first order model shows that the rate of drug released from matrice depends on the concentration of drug within the dissolution medium. For zero order model, drug release occurs rapidly after the drug dissociates, which implies that the rate of release is, in fact, independent of the concentration. Another model, the Korsmeyer-Peppas describes the release behaviour of drug from hydrophilic matrix and shows whether transport mechanism is 

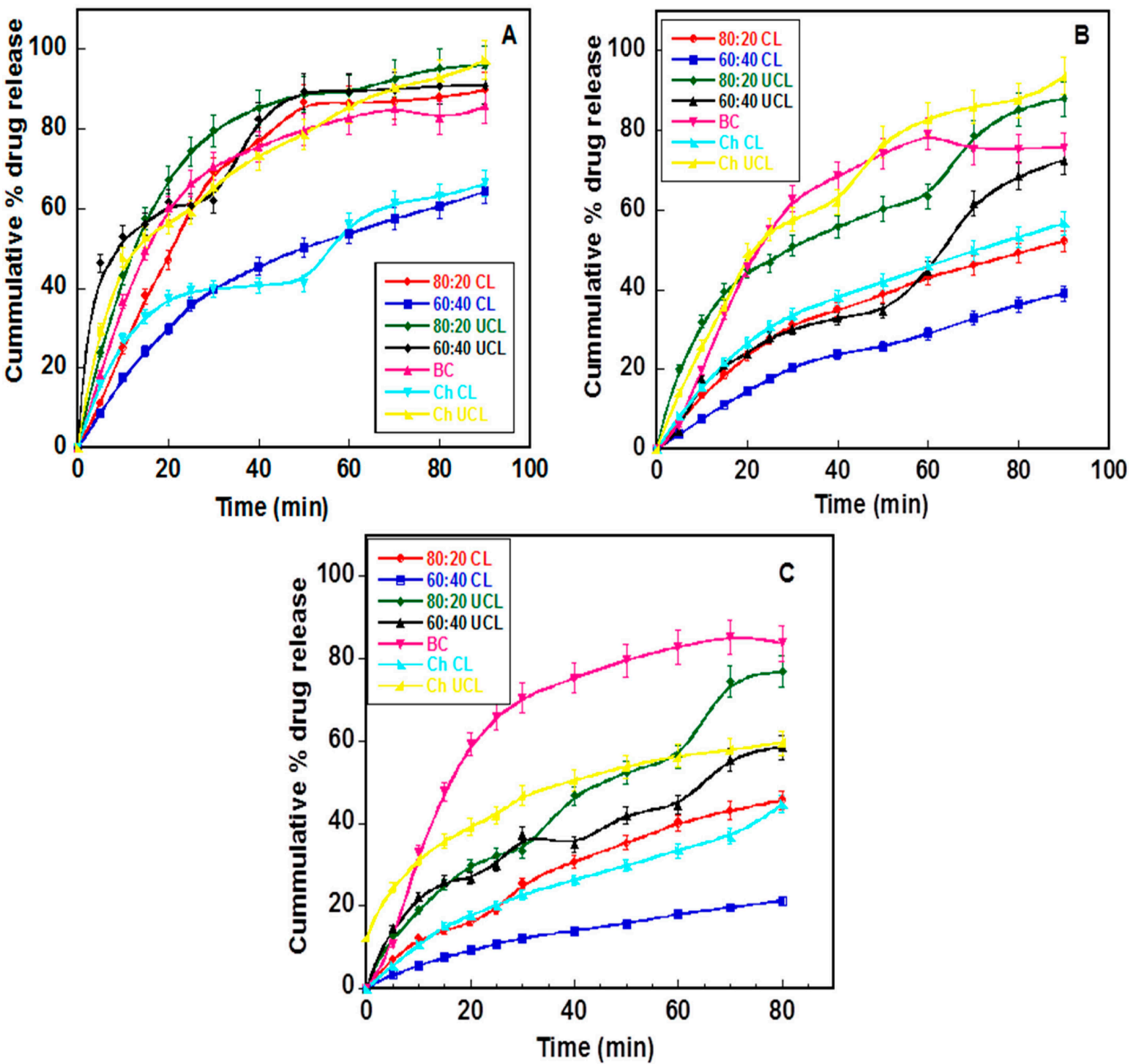

Figure 10. Drug release profile of $B C$, chitosan and $B C-C h(\% w / w)$ hydrogels $(n=3)$ at $(A) p H 1.0$ (B) pH 4.5 and (C) pH 6.8. (first value is $B C$ and last value is chitosan).

according to Fickian, non-Fickian, Case II or Super Case II. For any of the models to be valid, the plot of the drug release data with time should be linear. These models have been discussed in detail in the literature. ${ }^{[44-46]}$

The drug release profiles from the hydrogels were obtained over a 90 min period by measuring the UV absorbance of the drug in the different media used. The amount of drug released from the matrice was calculated from the calibration plot of UV absorbance against drug concentration. The cumulative $\%$ drug release was calculated using Equation 9.

Cumulative release $(\%)=$

$\frac{\text { volume of sample withrawn }}{\text { bath volume }} \times P(t-1)+P t$
Where: $\mathrm{Pt}=$ Percentage release at time, $\mathrm{t}$ and $\mathrm{P}(\mathrm{t}-1)=$ Percentage release previous to' $t$ '.

The drug released by $B C$ matrix shown in Figure $10 \mathrm{~A}-\mathrm{C}$ was observed to follow the Higuchi model indicating the drug release was via diffusion. The release exponent ( $n$ ) from Peppas power law showed that the drug release followed the anomalous transport mechanism with $0.5<\mathrm{n}<1 \quad(\mathrm{n}=0.94)$ at $\mathrm{pH} 4.5$ while the transport mechanism was a super case-Il at pH 1.0 and 6.8 with $n>1(n=1.03$ and 1.40 , respectively). This suggests that the transport mechanism of $B C$ becomes complex at low and high pH's. Interestingly, it can be observed that BC swelled more than other samples at $\mathrm{pH} 6.8$ but recorded not much difference in drug release when compared to other samples at $\mathrm{pH} 6.8$ (Figure $10 \mathrm{C}$ ). This is because swelling of $\mathrm{BC}$ was dependent on the solvent penetration into 


\begin{tabular}{|c|c|c|c|c|c|c|c|c|c|c|}
\hline \multirow[b]{2}{*}{ Hydrogels } & \multicolumn{2}{|c|}{ Zero order } & \multicolumn{2}{|c|}{ Kosymer-Peppas } & \multicolumn{2}{|c|}{ First Order Model } & \multicolumn{2}{|c|}{ Higuchi Model } & \multicolumn{2}{|c|}{ Hixson Model } \\
\hline & $\mathrm{R}^{2}$ & $\mathrm{~m}$ & $\mathrm{R}^{2}$ & $\mathrm{~m}$ & $\mathrm{R}^{2}$ & $\mathrm{~m}$ & $R^{2}$ & $\mathrm{~m}$ & $\mathrm{R}^{2}$ & $\mathrm{~m}$ \\
\hline & & & & pH 1.0 & & & & & & \\
\hline BC_Ch:80_20 CL & 0.798 & 0.954 & 0.919 & 0.955 & 0.925 & -0.112 & 0.931 & 10.874 & 0.892 & 0.029 \\
\hline BC_Ch:60_40 CL & 0.904 & 0.657 & 0.944 & 0.870 & 0.970 & -0.005 & 0.987 & 7.25 & 0.951 & 0.014 \\
\hline BC_Ch:80_20 UCL & 0.706 & 0.849 & 0.818 & 0.879 & 0.967 & -0.015 & 0.906 & 10.16 & 0.900 & 0.031 \\
\hline BC_Ch:60_40 UCL & 0.713 & 0.747 & 0.732 & 0.807 & 0.897 & -0.012 & 0.987 & 8.855 & 0.860 & 0.026 \\
\hline$B C$ & 0.711 & 0.784 & 0.953 & 0.962 & 0.886 & -0.009 & 0.905 & 9.341 & 0.835 & 0.023 \\
\hline $\mathrm{Ch} C L$ & 0.864 & 0.597 & 0.852 & 0.793 & 0.933 & -0.005 & 0.959 & 6.64 & 0.916 & 0.013 \\
\hline Ch UCL & 0.977 & 0.848 & 0.802 & 0.8458 & 0.960 & -0.015 & 0.954 & 9.721 & 0.927 & 0.031 \\
\hline \multicolumn{11}{|c|}{$\mathrm{pH} 4.5$} \\
\hline BC_Ch:80_20 CL & 0.923 & 0.536 & 0.960 & 0.836 & 0.968 & -0.003 & 0.990 & 5.865 & 0.955 & 0.011 \\
\hline BC_Ch:60_40 CL & 0.961 & 0.412 & 0.990 & 0.817 & 0.982 & -0.002 & 0.990 & 0.981 & 0.976 & 0.008 \\
\hline BC_Ch:80_20 UCL & 0.906 & 0.812 & 0.859 & 0.846 & 0.948 & -0.099 & 0.982 & 8.924 & 0.958 & 0.023 \\
\hline BC_Ch:60_40 UCL & 0.959 & 0.749 & 0.961 & 0.906 & 0.933 & -0.006 & 0.920 & 7.741 & 0.949 & 0.017 \\
\hline$B C$ & 0.747 & 0.820 & 0.813 & 0.839 & 0.832 & -0.008 & 0.896 & 9.482 & 0.809 & 0.205 \\
\hline $\mathrm{Ch} C \mathrm{~L}$ & 0.916 & 0.568 & 0.945 & 0.835 & 0.970 & -0.004 & 0.992 & 6.235 & 0.955 & 0.012 \\
\hline Ch UCL & 0.997 & 0.954 & 0.915 & 0.922 & 0.985 & -0.012 & 0.980 & 10.579 & 0.978 & -0.029 \\
\hline \multicolumn{11}{|c|}{ pH 6.8} \\
\hline BC_Ch:80_20 CL & 0.960 & 0.52 & 0.975 & 0.82 & 0.983 & -0.003 & 0.987 & 5.536 & 0.977 & 0.01 \\
\hline BC_Ch:60_40 CL & 0.957 & 0.233 & 0.996 & 0.686 & 0.97 & -0.001 & 0.992 & 2.505 & 0.966 & 0.004 \\
\hline BC_Ch:80_20 UCL & 0.969 & 0.84 & 0.905 & 0.990 & 0.965 & -0.007 & 0.964 & 8.845 & 0.975 & 0.026 \\
\hline BC_Ch:60_40 UCL & 0.921 & 0.572 & 0.951 & 1.102 & 0.961 & -0.004 & 0.978 & 6.224 & 0.952 & 0.012 \\
\hline$B C$ & 0.719 & 0.831 & 0.986 & 1.028 & 0.894 & -0.010 & 0.898 & 9.804 & 0.842 & 0.024 \\
\hline Ch CL & 0.972 & 0.486 & 0.980 & 0.813 & 0.983 & -0.003 & 0.972 & 5.135 & 0.981 & 0.009 \\
\hline Ch UCL & 0.812 & 0.556 & 0.878 & 0.812 & 0.978 & -0.010 & 0.965 & 6.417 & 0.873 & 0.012 \\
\hline
\end{tabular}

the $\mathrm{BC}$ porous network (matrix) while the drug release is influenced by $B C$ matrix in terms of swelling as well as the drug's solubility and diffusion in the solvent at that $\mathrm{pH}$.

The release from the non-crosslinked chitosan revealed a zero order model at pHs 1.0 and 4.5, suggesting a case of rapid or burst release because of chitosan being soluble in acidic media. At pH 6.8, first order model was followed, suggesting the release was dependent on the drug concentration within the matrix. The release exponent showed an anomalous transport mechanism at all pHs. For the crosslinked chitosan, drug release followed the first order model at all $\mathrm{pH}$ and the release exponent showed an anomalous transport mechanism at $\mathrm{pH} 6.8(\mathrm{n}=0.81-0.87)$ while a super case-Il transport mechanism ( $n=1.18$ and 1.3) was recorded at $\mathrm{pH}^{\prime} \mathrm{s} 4.5$ and 1.0.

There was no significant difference $(p<0.05)$ seen in the drug release for non-crosslinked $B C-C h$ samples. The drug release initially showed fast release at all $\mathrm{pH}$ (Figure 10A-C) which was highest at $\mathrm{pH} 1.0$ followed by $\mathrm{pH} 4.5$ and $\mathrm{pH} 6.8$, respectively. This is due to the interpenetration of polymer chains, their physical entanglements as well as the porosity in hydrogels, ${ }^{[4]}$ which was further enhanced by high hydrophilicity contribution from both $\mathrm{BC}$ and chitosan, respectively.

In the crosslinked $\mathrm{BC}-\mathrm{Ch}$ hydrogels, the crosslinking reaction involving chitosan and genipin brought about the formation of hydrophilic and hydrophobic interactions, ${ }^{[48]}$ within the entire hydrogel network. The coexistence of these two interactions (introduction of hydrophobic unit) resulted in a decrease in drug release due to decrease in the total porosity (initial porosity plus porosity due to drug dissolution) of the matrix. The drug released from all the crosslinked hydrogels matrix was slow at all $\mathrm{pH}$, except at $\mathrm{pH} 1.0$ for $\mathrm{BC}-\mathrm{Ch} 80: 20$ which was significantly different $(p>0.05)$. This is attributed to high amount of $\mathrm{BC}$ which may have hindered, to some extent, adequate crosslinking interaction between chitosan and genipin via masking effect.

The drug release kinetics data obtained from the different models showed that all crosslinked hydrogels (with the exception of first order kinetic model shown by BC-Ch 80:20 at $\mathrm{pH}$ 6.8) followed the Higuchi model (Figure $11 \mathrm{~A}$ ), suggesting that matrixes were diffusion controlled as plots of the cumulative \% drug release versus square root of time (SQRT) were found to be linear, and the correlation coefficient $\left(R^{2}\right)$ higher than those of other models as shown in Table 2. Noncrosslinked $\mathrm{BC}-\mathrm{Ch}$ 80:20 at $\mathrm{pH} 1.0$ followed the first order kinetic model (Figure $8 \mathrm{~B}$ ) while BC-Ch 60:40 UCL at pH 4.5 was found to be of zero order (Figure $11 \mathrm{C}$ and Table 2).

From Korsmeyer-Peppas power law, all crosslinked hydrogels and non-crosslinked samples at $\mathrm{pH} 4.5$ recorded release exponents (n) $0.5<n<1(n=0.82-0.92)$. This is a case of nonFickian or anomalous transport, ${ }^{[44,49-51]}$ and the drug release is brought about by the processes of diffusion and swelling within the hydrogels matrice. The slow rearrangement of the polymeric chains and the diffusion process simultaneously caused the time-dependent anomalous effects. This anomalous transport mechanism indicates that the velocity of the buffer ( $\mathrm{pH}$ 4.5) diffusing into the matrix and the polymer relaxation processes are similar in magnitudes.

At $\mathrm{pH} 1.0$, all non-crosslinked $\mathrm{BC}-\mathrm{Ch}$ samples had release exponents $(n)$ of $0.5<n<1,(n=0.81-0.88)$ which suggests that the drug release mechanism followed a non-Fickian or 

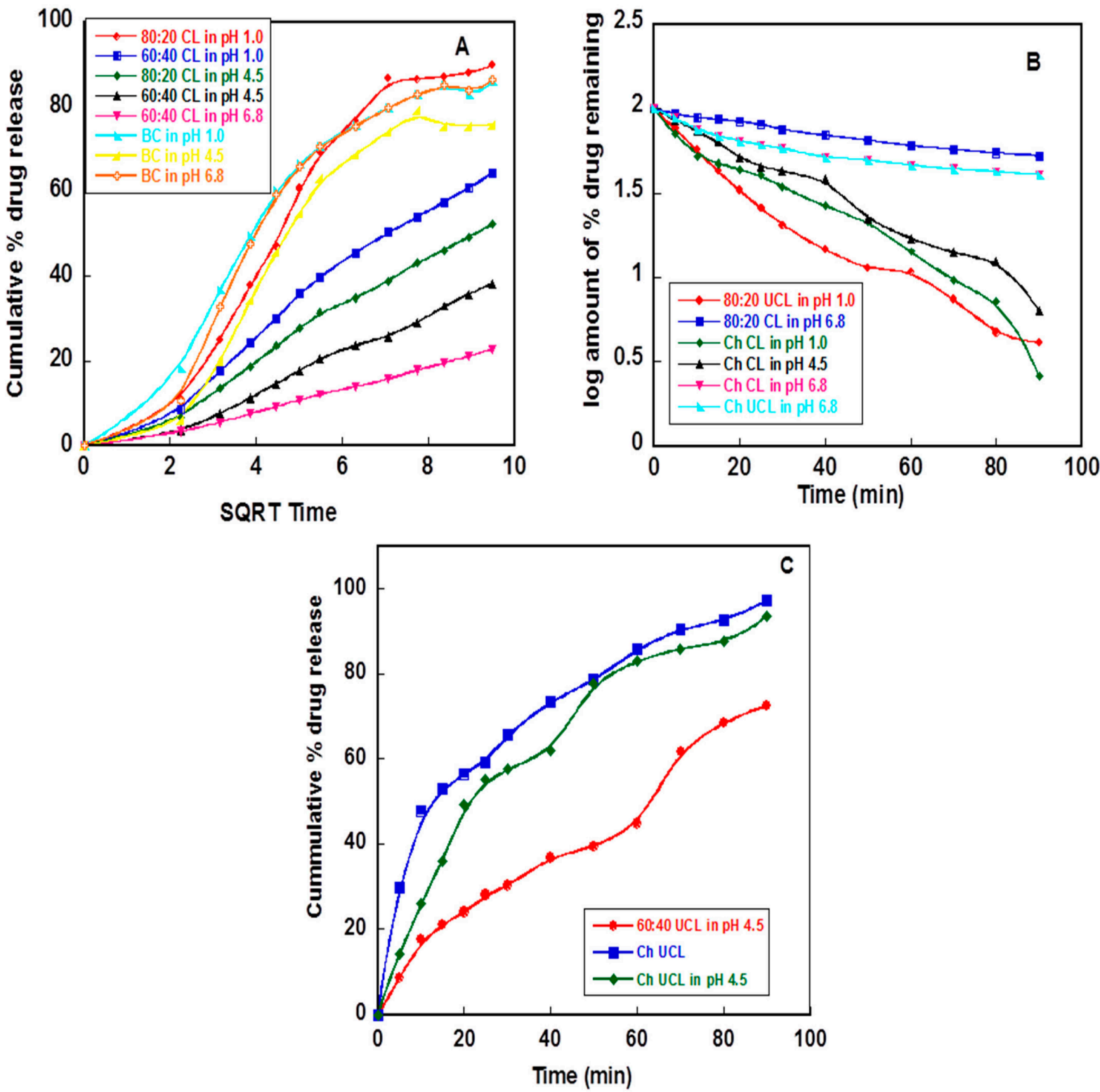

Figure 11. Kinetic models for QF release in artificial gastrointestinal fluids from different matrixes. (A) Higuchi (B) First order (C) Zero order. (For each BC-Ch (\% $\mathrm{w} / \mathrm{w})$, the first value is $B C$ and the last value is chitosan

anomalous transport in which the release was governed by both diffusion and swelling. However, with the crosslinked hydrogels, the transport mechanism changed from anomalous to a Super Case II $(n>1)$, with release exponents of 1.03 and 1.36 respectively. This is an extreme form of transport, which implies that the drug release mechanism was both by diffusion and polymer chain relaxation. As stated hitherto, this behaviour could be due to the fact that at the point of the sorption process, tension and relaxation of the polymer chains (solvent crazing) ${ }^{[4]}$ occurred in the hydrogels. Further elucidation may suggest chain rearrangements emanating from the crosslinking of the $\mathrm{NH}_{2}$ group in chitosan by genipin which altered the nature of interpenetration and entanglements compared to that present in the non-crosslinked samples, making the outer layer of the hydrogels to limit/or prevent axial swelling of the gels, yielding tension of compression on the hydrogel nucleus. ${ }^{[4,45]}$ As the polymeric interface gel-vitreous moved to the nucleus, the tension increased until the nucleus broke. More so, this observed release transport mechanism may be linked to the velocity of the $\mathrm{pH} 1.0$ medium-diffusion which is much higher, causing an acceleration of the solvent penetration due to low $\mathrm{pH}$.

At $\mathrm{pH} 6.8$, the release mechanisms were similar to those at pHs 1.0 and 4.5. The crosslinked hydrogels followed a nonFickian transport with values 0.67 and $0.82(0.5<n<1)$; the non-crosslinked samples showed release exponents $n>1$ with values 1.10 and 1.12, the so called Super Case II transport mechanism. 
The drug release from the hydrogels matrice at different $\mathrm{pHs}$ revealed that the percentage of drug released decreased as $\mathrm{pH}$ increased for both crosslinked hydrogels and noncrosslinked samples, except for non-crosslinkedd BC-Ch 60:40 which showed a different behaviour at $\mathrm{pH}$ 6.8. However, tthrough crosslinking and changing the composition of the hydrogels, the drug release mechanism changed. These hydrogel systems possess potential application in pharmaceutical field as all chemicals used in the development of the hydrogels are non-toxic and are also biocompatible with extracellular tissues.

Low swelling hydrogels have been reported to possess various advantages, ${ }^{[22]}$ due to decrease in the relaxation of polymers chains as a result of crosslinking which results in lesser swelling. In the present study, the hydrogel demonstrate ability to slowly release drug in controlled manner demonstrating it may be suitable for the administration of QF for the treatment of Schizophrenia, with prolonged efficacy and decreased toxicity, especially for the elderly people who normally skip doses because of cognitive problems.

\section{Conclusion}

$B C$ was produced from coconut water by fermenting with the bacteria Gluconacetobacter xylinus. Semi-IPN hydrogels were prepared by mixing the $\mathrm{BC}$ with chitosan and selectively crosslinking the chitosan with genipin. The FT-IR of the semiIPN revealed shifts in the peak intensity at $1600 \mathrm{~cm}^{-1}$ and the emergence of the peak at $1500 \mathrm{~cm}^{-1}$ emanating from the crosslinking reaction of chitosan with genipin. The swelling behaviour of crosslinked hydrogels and non-crosslinked samples increased with higher chitosan contents at low pH's while at high $\mathrm{pH}$ 's, the swelling increased with increasing amount of BC. The swelling of crosslinked hydrogels were lower than those of the non-crosslinked samples. The in vitro release kinetic of QF showed that non-crosslinked samples released the drug faster from their matrice. Crosslinked hydrogels showed controlled release. The drug release kinetics from the crosslinked hydrogels followed predominantly, the Higuchi model in all media and the transport mechanism showed that the release exponent of the hydrogels were a combination of nonFickian and Super Case II transport, indicating a possible case of complex transport mechanism. Crosslinked BC-Ch 60:40 hydrogel showed the most promising potential in controlling the drug release in different media. The results show that BCCh semi-IPN hydrogels have potentials as drug carriers.

\section{Supporting Information Summary}

Supporting information PDF file contains materials and detailed experimental procedures for the preparation of $G$. xylinus inoculum, synthesis of $B C$, preparation of $B C-C h$ hydrogels, characterization of hydrogels using FTIR, DSC, SEM, swelling ratio and gel fraction as well as the drug loading and release for hydrogel matrice.

\section{Acknowledgements}

The sponsorship of the Commonwealth Commission and the financial support of The University of the South Pacific Research Committee are highly recognised and appreciated.

\section{Conflict of Interest}

The authors declare no conflict of interest.

Keywords: Bacterial cellulose - Chitosan - Drug release Genipin · Hydrogels

[1] P. R. Chawla, I. B. Bajaj, S. A. Survase, R. S. Singhal, Food Technol. Biotechnol. 2009, 47, 107-124.

[2] L. Huang, X. Chen, T. X. Nguyen, H. Tang, L. Zhang, G. Yang, J. Mater. Chem. B 2013, 1, 2976-2984.

[3] H. G. de Oliveira Barud, R. R. da Silva, H. da Silva Barud, A. Tercjak, J. Gutierrez, W. R. Lustri, O. B. de Oliveira, S. J. L. Ribeiro, Carbohydr. Polym. 2016, 153, 406-420.

[4] A. M. A. Gallegos, S. Herrera Carrera, R. Parra, T. Keshavarz, H. M. N. Iqbal, BioResources 2016, 11, 5641-5655.

[5] X. Shen, J. L. Shamshina, P. Berton, G. Gurau, R. D. Rogers, Green Chem. 2016, 18, 53-75.

[6] F. Esa, S. M. Tasirin, N. A. Rahman, Agric. Agric. Sci. Procedia 2014, 2, 113119.

[7] W.-C. Lin, C.-C. Lien, H.-J. Yeh, C.-M. Yu, S. Hsu, Carbohydr. Polym. 2013, 94, 603-611.

[8] M. Shoda, Y. Sugano, Biotechnol. Bioprocess Eng. 2005, 10, 1-8.

[9] H.-J. Son, M.-S. Heo, Y.-G. Kim, S.-J. Lee, Biotechnol. Appl. Biochem. 2001, 33, 1-5.

[10] G. F. Picheth, C. L. Pirich, M. R. Sierakowski, M. A. Woehl, C. N. Sakakibara, C. F. de Souza, A. A. Martin, R. da Silva, R. A. de Freitas, Int. J. Biol. Macromol. 2017, 104, 97-106.

[11] M. UI-Islam, T. Khan, J. K. Park, Carbohydr. Polym. 2012, 88, 596-603.

[12] D. Klemm, B. Heublein, H.-P. Fink, A. Bohn, Angew. Chem. Int. Ed. 2005, 44, 3358-3393.

[13] A. Svensson, E. Nicklasson, T. Harrah, B. Panilaitis, D. L. Kaplan, M. Brittberg, P. Gatenholm, Biomaterials 2005, 26, 419-431.

[14] S. Torgbo, P. Sukyai, Appl. Mater. Today 2018, 11, 34-49.

[15] M. Fürsatz, M. Skog, P. Sivlér, E. Palm, C. Aronsson, A. Skallberg, G. Greczynski, H. Khalaf, T. Bengtsson, D. Aili, Biomed. Mater. 2018, 13, 25014-25025.

[16] J. Kucińska-Lipka, I. Gubanska, H. Janik, Polym. Bull. 2015, 72, 2399-2419.

[17] I. Sulaeva, U. Henniges, T. Rosenau, A. Potthast, Biotechnol. Adv. 2015, $33,1547-1571$.

[18] R. A. A. Muzzarelli, C. Muzzarelli, in Polysacch. I (Ed.: T. Heinze), SpringerVerlag, Berlin/Heidelberg, 2005, pp. 151-209.

[19] M. N. V. R. Kumar, R. A. A. Muzzarelli, C. Muzzarelli, H. Sashiwa, A. J. Domb, Chem. Rev. 2004, 104, 6017-6084.

[20] Q. Li, X. Wang, X. Lou, H. Yuan, H. Tu, B. Li, Y. Zhang, Carbohydr. Polym. $2015,130,166-174$.

[21] R. A. A. Muzzarelli, Carbohydr. Polym. 2009, 77, 1-9.

[22] D. R. Rohindra, A. V. Nand, J. R. Khurma, S. Pac. J. Nat. Sci. 2004, 22, $32-$ 35.

[23] J. R. Khurma, D. R. Rohindra, A. V. Nand, Polym. Bull. 2005, 54, 195-204.

[24] Y. Jia, X. Wang, M. Huo, X. Zhai, F. Li, C. Zhong, Nanomater. Nanotechnol. $2017,7,1-8$.

[25] M. A. Johns, Y. Bae, F. E. G. Guimarães, E. M. Lanzoni, C. A. R. Costa, P. M. Murray, C. Deneke, F. Galembeck, J. L. Scott, R. I. Sharma, ACS Omega 2018, 3, 937-945.

[26] F. Wahid, X.-H. Hu, L.-Q. Chu, S.-R. Jia, Y.-Y. Xie, C. Zhong, Int. J. Biol. Macromol. 2019, 122, 380-387.

[27] H. J. Kim, J. N. Jin, E. Kan, K. J. Kim, S. H. Lee, Biotechnol. Bioprocess Eng. 2017, 22, 89-94.

[28] S. Papadimitriou, D. Bikiaris, K. Avgoustakis, E. Karavas, M. Georgarakis, Carbohydr. Polym. 2008, 73, 44-54. 
[29] J. Liang, R. Wang, R. Chen, Polymers 2019, 11, 491-505.

[30] P. Aramwit, T. Siritienthong, T. Srichana, J. Ratanavaraporn, Cells Tissues Organs 2013, 197, 224-238.

[31] K. Pal, A. T. Paulson, D. Rousseau, in Handb. Biopolym. Biodegrad. Plast., Elsevier, 2013, pp. 329-363.

[32] H. M. C. De Azeredo, M. F. Rosa, M. De Sá, M. Souza Filho, K. W. Waldron, in Adv. Biorefineries, Elsevier, 2014, pp. 819-874.

[33] A. N. B. Romainor, S. F. Chin, S. C. Pang, L. M. Bilung, J. Nanomater. 2014, 2014, 1-10.

[34] M. Akhlaq, F. Maryam, A. Elaissari, H. Ullah, M. Adeel, A. Hussain, M. Ramzan, O. Ullah, M. Zeeshan Danish, S. Iftikhar, Drug Deliv. 2018, 25, 916-927.

[35] M. Taskeen, M. Tirunagari, Husna. K. Qureshi, ACTA Pharm. Sci. 2017, 55, 21-37.

[36] S. Yano, H. Maeda, M. Nakajima, T. Hagiwara, T. Sawaguchi, Cellulose 2008, 15, 111-120.

[37] R. R. Mohamed, R. S. Seoudi, Magdy. W. Sabaa, Cellulose 2012, 19, 947958.

[38] H. M. C. Azeredo, H. Barud, C. S. Farinas, V. M. Vasconcellos, A. M. Claro, Front. Sustain. Food Syst. 2019, 3, 1-14.

[39] A. F. S. Costa, F. C. G. Almeida, G. M. Vinhas, L. A. Sarubbo, Front. Microbiol. 2017, 8, 1-12.
[40] B. Lindman, B. Medronho, L. Alves, C. Costa, H. Edlund, M. Norgren, Phys. Chem. Chem. Phys. 2017, 19, 23704-23718.

[41] C. N. Costa, V. G. Teixeira, M. C. Delpech, J. V. S. Souza, M. A. S. Costa, Carbohydr. Polym. 2015, 133, 245-250.

[42] T. Wang, S. Gunasekaran, J. Appl. Polym. Sci. 2006, 101, 3227-3232.

[43] A. S. Hoffman, Adv. Drug Deliv. Rev. 2002, 54, 3-12.

[44] M. L. Bruschi, Elsevier, 2015, pp. 63-86.

[45] R. Gouda, H. Baishya, Z. Qing, J. Dev. Drugs 2017, 6, 1-8.

[46] N. A. Peppas, J. J. Sahlin, Int. J. Pharm. 1989, 57, 169-172.

[47] R. . B. Baggi, N. . B. Kilaru, Asian J. Pharm. Technol. 2016, 6, 223-230.

[48] L. Mengatto, M. G. Ferreyra, A. Rubiolo, I. Rintoul, J. Luna, Mater. Chem. Phys. 2013, 139, 181-186.

[49] P. Costa, J. M. Sousa Lobo, Eur. J. Pharm. Sci. 2001, 13, 123-133.

[50] P. L. Ritger, N. A. Peppas, J. Controlled Release 1987, 5, 23-36.

[51] D. Sahu, Pharm. Sin. 2010, 1, 48-57.

[52] G. Z. Kyzas, D. N. Bikiaris, N. K. Lazaridis, Langmuir 2008, 24, 4791-4799.

Submitted: June 21, 2019

Accepted: August 23, 2019 